\title{
Is there a relationship between narcolepsy, multiple sclerosis and HLA-DQB1*06:02?
}

\author{
Existe relação entre narcolepsia, esclerose múltipla e HLA-DQB1*06:02? \\ Paulo José Lorenzoni', Lineu Cesar Werneck', Ana Christina de Souza Crippa ${ }^{1}$, Alessandra Zanatta', \\ Cláudia S. Kamoi Kay', Carlos Eduardo S. Silvado', Rosana Herminia Scola ${ }^{1}$
}

\begin{abstract}
We studied multiple sclerosis (MS) patients with the HLA-DQB1*06:02 allele and compared them with MS patients who did not carry the HLA-DQB1*06:02 allele. We analyzed clinical and neurophysiological criteria for narcolepsy in six MS patients with HLA-DQB1*06:02, compared with $12 \mathrm{MS}$ patients who were HLA-DQB1*06:02 non-carriers. Only two patients with HLA-DQB1*06:02 allele scored higher than 10 on the Epworth Sleepiness Scale. Polysomnography recording parameters and the multiple sleep latency test showed an absence of narcolepsy in the study group. Our study suggested no significant correlation between narcolepsy, MS and HLA-DQB1*06:02. The HLA-DQB1*06:02 allele alone was not sufficient to cause MS patients to develop narcolepsy.
\end{abstract}

Keywords: narcolepsy; multiple sclerosis; human leukocyte antigen; polysomnography.

\section{RESUMO}

Pacientes com esclerose múltipla (EM) portadores do alelo HLA-DQB1*06:02 foram estudados e comparados com pacientes com EM mas que não são portadores do alelo HLA-DQB1*06:02. Os critérios clínicos e neurofisiológicos para narcolepsia foram analisados em pacientes com EM sendo 6 pacientes com o HLA-DQB1*06:02 comparados a 12 pacientes sem o HLA-DQB1*06:02. Somente 2 pacientes com EM e HLA-DQB1*06:02 tiveram escore maior que 10 na escala "Epworth Sleepiness Scale". Os parâmetros da polissonografia e o teste de múltiplas latências do sono mostraram ausência de narcolepsia no grupo estudo. Nosso estudo não sugere correlações significantes entre narcolepsia, EM e HLA-DQB1*06:02. Somente o HLA-DQB1*06:02 não foi suficiente para desenvolver narcolepsia em pacientes com EM.

Palavras-chave: narcolepsia; esclerose múltipla; antígeno leucocitário humano); polissonografia.

The DQB1*06:02 allele of the human leukocyte antigen (HLA) class II is a well-known genetic risk factor for narcolepsy $y^{1,2,3}$. In addition, the HLA-DQB1*06:02 allele influences the susceptibility and severity of multiple sclerosis (MS) ${ }^{1,2,3}$. However, few reports have described the co-occurrence of both disorders and in many of them, the HLA class was not described ${ }^{4,5,6}$. For that reason, at the moment, it is difficult to conclude whether this was a coincidental finding, or whether the development of narcolepsy in MS patients was influenced by their HLA-DQB1 allele status.

The main objective of this study was to investigate the potential relationship between the HLA-DQB1*06:02 allele, narcolepsy, and MS.

\section{METHODS}

We studied patients who were diagnosed with MS, based on the $2010 \mathrm{McDonald}$ criteria, and divided them into two groups according HLA-DQB1 status: a study group with HLA-DQB1*06:02 and a control group with other HLA-DQB1 subtypes.

Relevant data, including age, gender, time-period of disease progression (MS follow-up time), MS subtype, Expanded Disability Status Scale (EDSS) score, Epworth Sleepiness Scale (ESS) score, polysomnography (PSG), and the multiple sleep latency test (MSLT) were recorded.

The ESS was performed in both groups to identified narcolepsy and scores higher than 10 on the ESS was considered indicative of narcolepsy, according to the International Classification of Sleep Disorders (ICSD-3) 7 .

Polysomnography and the MSLT were performed in the study group, according to standard procedures. The PSG was considered diagnostic of narcolepsy when it indicated short sleep latency, excessive sleep disruption with frequent arousal and increased total sleep time ${ }^{4,7}$. The MSLT was considerate diagnostic of narcolepsy if sleep onset latency was $<8$ minutes and two or more sleep-onset REM were present, according to the ICSD-3 criteria ${ }^{4,7}$.

'Universidade Federal do Paraná, Hospital de Clínicas, Departamento de Medicina Interna, Serviço de Neurologia, Curitiba PR, Brasil.

Correspondence: Rosana Herminia Scola; Serviço de Neurologia do Hospital de Clínicas da UFPR; Rua General Carneiro, 181 / $3^{\circ}$ andar; $80060-900$ Curitiba PR, Brasil; E-mail: rosana.scola@hc.ufpr.br

Conflict of interest: There is no conflict of interest to declare.

Support: This study was supported by Fundação Araucária, CAPES and CNPq.

Received 16 May 2016; Received in final form 23 September 2016; Accepted 14 March 2017. 
The presence of HLA-DQB1*06:02 was determined by direct sequencing of exons 2 and 3 of the $H L A-D Q B 1$ gene [OMIM 604305] using an ABI PRISM 3100 Avant Genetic Analyzer.

The data were analyzed using descriptive statistical methods and Fisher's exact test.

All studies were conducted after patient informed consent was obtained.

\section{RESULTS}

Twenty-five of $85 \mathrm{MS}$ patients had at least one copy of the HLA-DQB1*06:02 allele (five were homozygous). We included six patients in the study group and excluded the remaining patients because they were unable to attend an appointment to perform PSG or the MSLT, did not give consent or had concomitant psychiatric disorders. We included $12 \mathrm{MS}$ patients who did not carry the HLA-DQB1*06:02 allele in the control group. Table 1 shows the HLA-DQB1 alleles distribution frequencies of both groups.

The sample consisted of 18 patients (13 females and five males), aged from 23 to 65 years (median 47; mean $44.9 \pm 11.6$ ). The time period of disease progression varied between 29 and 224 months with a mean time of 127.05 months. The MS subtype was relapsing-remitting in 14 patients, secondary progressive in three patients and primary progressive in one patient. The median EDSS score was 3.5 ( 0 to 9.0 , mean $4.27 \pm 2.74$ ). The median ESS score was 8 ( 0 to 17 , mean $7.66 \pm 4.45$ ).

The two groups were compared with respect to gender, age, MS follow-up time, MS subtype, EDSS score and ESS score (Table 2).

Table 1. HLA-DQB1 alleles of the multiple sclerosis patients.

\begin{tabular}{|c|c|c|}
\hline \multirow{2}{*}{ Case } & \multicolumn{2}{|c|}{ HLA-DQB1 } \\
\hline & Allele 1 & Allele 2 \\
\hline \multicolumn{3}{|c|}{ Study group } \\
\hline 1 & 02:01 & 06:02 \\
\hline 2 & 04:02 & 06:02 \\
\hline 3 & 04:02 & 06:02 \\
\hline 4 & 03:01 & 06:02 \\
\hline 5 & 06:02 & 06:02 \\
\hline 6 & 02:01 & 06:02 \\
\hline \multicolumn{3}{|c|}{ Control group } \\
\hline 1 & 02:03 & 06:08 \\
\hline 2 & 02:01 & 05:02 \\
\hline 3 & 06:08 & 06:08 \\
\hline 4 & 05:01 & 05:03 \\
\hline 5 & 04:02 & 04:02 \\
\hline 6 & 05:02 & 06:05 \\
\hline 7 & 03:02 & 06:01 \\
\hline 8 & 03:02 & 03:02 \\
\hline 9 & 02:03 & 03:04 \\
\hline 10 & 03:01 & 06:03 \\
\hline 11 & 03:02 & 03:02 \\
\hline 12 & 02:02 & 03:02 \\
\hline
\end{tabular}

Only two patients in the study group (HLA-DQB1*06:02) scored higher than 10 on the ESS compared with five patients in the control group, but this difference did not reach statistical significance $(p=0.5724)$. Figure shows the ESS score for both groups.

The PSG recording parameters, performed in five patients, revealed an absence of narcolepsy criterion in the study group, according to the ICSD-37. Table 3 shows the range of PSG recording parameters in the study group.

The MSLT was performed in five patients and showed an absence of narcolepsy criterion in all patients, according to the ICSD- $3^{7}$. For the MSLT, Table 3 shows normal mean sleep onset latency as well as an absence of sleep-onset REM episodes in all studied patients.

Table 2. Characteristics of the multiple sclerosis patients in the study group ( $n=6)$ and control group $(n=12)$.

\begin{tabular}{|c|c|c|}
\hline Variable & Study group* & Control group \\
\hline Gender (F:M) & 04:02 & 09:03 \\
\hline \multicolumn{3}{|l|}{ Age (years) } \\
\hline Mean + SD & $46.0 \pm 10.7$ & $44.3 \pm 12.5$ \\
\hline Median (range) & $45(33-64)$ & $47(23-65)$ \\
\hline \multicolumn{3}{|c|}{ Follow up time (month) } \\
\hline Mean + SD & $131.3 \pm 55.7$ & $124.9 \pm 47.7$ \\
\hline Median (range) & $123(64-224)$ & $130(29-180)$ \\
\hline \multicolumn{3}{|l|}{ MS subtype } \\
\hline $\mathrm{RR}$ & 5 & 9 \\
\hline SP & 1 & 2 \\
\hline PP & 0 & 1 \\
\hline \multicolumn{3}{|l|}{ EDSS score } \\
\hline Mean + SD & $4.41 \pm 2.81$ & $3.83 \pm 2.81$ \\
\hline Median (range) & $4.25(1.0-8.5)$ & $3.5(0.0-9.0)$ \\
\hline \multicolumn{3}{|l|}{ ESS score } \\
\hline Mean + SD & $7 \pm 4.85$ & $8 \pm 4.43$ \\
\hline Median (range) & $6.5(1-13)$ & $8(0-17)$ \\
\hline$>10$ points & 2 & 5 \\
\hline $\begin{array}{l}\text { *HLA-DQB1*06:02; } \\
\text { relapsing-remitting; } \\
\text { EDSS: expanded disa } \\
\text { SD: standard deviation }\end{array}$ & $\begin{array}{l}\text { male; MS: mu } \\
\text { progressive; PP: } \\
\text { cale; ESS: Epwo }\end{array}$ & $\begin{array}{l}\text { le sclerosis; RR } \\
\text { imary progressive } \\
\text { Sleepiness Scale }\end{array}$ \\
\hline
\end{tabular}

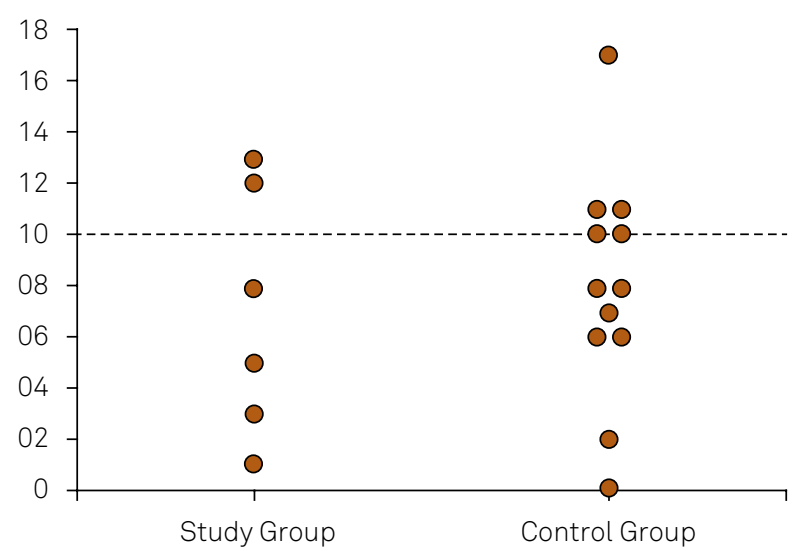

Figure. Epworth Sleepiness Scale (ESS) scores of patients studied with HLA-DQB1*06:02 (study group) and without HLA-DQB1*06:02 (control group). The line indicates a score of 10 (considered to identify narcolepsy according to the ICSD-3). 
Table 3. The PSG and MSLT features of the MS patients in the study group ( $n=5)$.

\begin{tabular}{|c|c|c|c|c|c|c|}
\hline Case & 1 & 2 & 3 & 4 & 5 & Normal \\
\hline \multicolumn{7}{|l|}{ PSG features } \\
\hline Total sleep time (min) & 393 & 328 & 314 & 409 & 218 & \\
\hline Sleep efficiency (\%) & 80.1 & 70.27 & 85.0 & 83.05 & 52.72 & $>85$ \\
\hline Arousal index (N/h) & 8.2 & 7.9 & 15.5 & 27.7 & 14.3 & \\
\hline Sleep onset latency (min) & 15.0 & 101.5 & 14.5 & 10.0 & 115.0 & $<30$ \\
\hline Wake time after sleep onset (min) & 49.2 & 139.0 & 55.5 & 83.5 & 195.5 & \\
\hline Stage I (\% TST) & 8.2 & 15.0 & 5.5 & 20.5 & 13.7 & $2-5$ \\
\hline Stage II (\% TST) & 26.0 & 21.2 & 45.1 & 1.3 & 24.2 & $45-55$ \\
\hline Stage III (\% TST) & 23.7 & 27.8 & 4.3 & 10.0 & 14.0 & $3-8$ \\
\hline REM sleep (\% TST) & 18.3 & 6.3 & 30.0 & 61.2 & 0.8 & $20-25$ \\
\hline REM onset sleep latency (min) & 123.2 & 118.5 & 14.5 & 84.8 & 408.5 & $70-90$ \\
\hline \multicolumn{7}{|l|}{ MSLT features } \\
\hline Mean sleep latency onset (min) & 16.4 & 14.2 & 15.4 & 12.0 & 20.0 & $>8$ \\
\hline Sleep onset REM episodes & 0 & 0 & 0 & 0 & 0 & $<1$ \\
\hline
\end{tabular}

\section{DISCUSSION}

Somestudies haveinvestigated sleep disordersin MS patients, but narcolepsy remains a rare manifestation. To our knowledge, approximately 16 patients with concomitant narcolepsy have been reported to date, even though a high number of MS patients present with excessive daytime sleepiness ${ }^{4,8}$. Thus, the prevalence of narcolepsy is low for MS patients ( 0 to $1.6 \%$ ), but only two studies were considered in this estimate ${ }^{8,9}$.

Currently, there are no specific guidelines for the investigation of sleep disorders in MS. Clinical and laboratory examination for other causes of sleepiness are generally recommended, and sleep-specific studies may be required to diagnose possible narcoleptic patients ${ }^{1,7}$.

Human leukocyte antigen has been described as a predisposing factor in the co-occurrence of MS and narcolepsy in a small number of patients ${ }^{4,5,6,10}$. The HLA-DQB1*06:02 was reported only in three patients with both disorders ${ }^{5,6,10}$; HLA-DRB1*15:01 was reported in two patients with concomitance of both disorders, but in combination with HLA-DQB1*06:024,5,10. Therefore, in these cases, narcolepsy still seems to have a stronger association with HLA-DQB1*06:02 than with HLA-DRB1*15:01*5,10.
Other sporadic HLA alleles were also described as predisposing factors in this association between narcolepsy and MS4.

In the study group, neither short sleep latency nor sleep-onset REM, which are required for the diagnosis of narcolepsy, occurred during the MSLT. Also in this group, there was no correlation between high ESS scores and the MSLT results. We additionally looked for the presence of REM sleep latency $\leq 14$ minutes during nocturnal PSG, which might suggest narcolepsy, but this abnormality was present in only one of our patients? ${ }^{7}$. In this way, our findings on PSG and MSLT confirm previous studies that narcolepsy has rarely been found in MS patients, but also suggest that the presence of the DQB1*06:02 allele alone is not sufficient to cause narcolepsy in MS patients ${ }^{8}$.

Our series did not suggest a significant relationship between narcolepsy, MS and HLA-DQB1*06:02. Therefore, this study showed that narcolepsy in MS patients may yet be coincidental in the presence of HLA-DQB1*06:02, based on the most widely-used scale for narcolepsy (ESS) and neurophysiological studies (PSG and MSLT). Although the small number of MS patients with HLA-DQB1*06:02 could influence our findings, these data suggest that HLA-DQB1*06:02 alone is not sufficient for MS patients to develop narcolepsy.

\section{References}

1. Alóe F, Alves RC, Araújo JF, Azevedo A, Bacelar A, Bezerra $M$ et al. [Brazilian guidelines for the diagnosis of narcolepsy]. Rev Bras Psiquiatr. 2010;32(3):294-304. Portuguese. http://dx.doi.org/10.1590/S1516-44462010005000014

2. Nishino S, Kanbayashi T. Symptomatic narcolepsy, cataplexy and hypersomnia, and their implications in the hypothalamic hypocretin/orexin system. Sleep Med Rev. 2005;9(4):269-310. https://doi.org/10.1016/j.smrv.2005.03.004

3. Mahlios J, De la Herrán-Arita AK, Mignot E. The autoimmune basis of narcolepsy. Curr Opin Neurobiol. 2013;23(5):767-73.

https://doi.org/10.1016/j.conb.2013.04.013
4. Veauthier C. Sleep disorders in multiple sclerosis: review. Curr Neurol Neurosci Rep. 2015;15(5):21. https://doi.org/10.1007/s11910-015-0546-0

5. Vrethem M, Malmgren K, Lindh J. A patient with both narcolepsy and multiple sclerosis in association with Pandemrix vaccination. J Neurol Sci. 2012;321(1-2):89-91. https://doi.org/10.1016/j.jns.2012.07.025

6. Vetrugno R, Stecchi S, Plazzi G, Lodi R, D’Angelo R, Alessandria M et al. Narcolepsy-like syndrome in multiple sclerosis. Sleep Med. 2009;10(3):389-91. https://doi.org/10.1016/j.sleep.2008.03.009

7. American Academy of Sleep Medicine. International classification of sleep disorders, 3rd ed: diagnostic and coding manual. Darien: American Academy of Sleep Medicine; 2014. 
8. Poirier G, Montplaisir J, Dumont M, Duquette P, Décary F,

Pleines $J$ et al. Clinical and sleep laboratory study of narcoleptic symptoms in multiple sclerosis. Neurology. 1987;37(4):693-5. https://doi.org/10.1212/WNL.37.4.693

9. Marrie RA, Reider N, Cohen J, Trojano M, Sorensen PS,

Cutter $G$ et al. A systematic review of the incidence and prevalence of sleep disorders and seizure disorders in multiple sclerosis. Mult Scler. 2015;21(3):342-9. https://doi.org/10.1177/1352458514564486

10. Peraita-Adrados R, Lammers GJ, De Andrés C, Santamaría J, Vicario JL, Tafti M. A patient with narcolepsy with cataplexy and multiple sclerosis: two different diseases that may share pathophysiologic mechanisms? Sleep Med. 2013;14(7):695-6. https://doi.org/10.1016/j.sleep.2013.03.015 